\title{
HET ARREST VAN DE ONDERNEMINGSKAMER INZAKE DE JAARREKENING 1978 VAN PAKHOED
}

\author{
door Mr. Drs. H. Beckman
}

\section{Inleiding}

Op 29 mei 1980 heeft de Ondernemingskamer inzake de door Sobi tegen Pak. hoed aangespannen jaarrekeningprocedure uitspraak gedaan. In deze procedure komen - na vermindering van eis - de volgende bezwaren/vorderingen van Sobi aan de orde:

- de aanwijzingen van de OK, gegeven in de jaarrekeningprocedure 1977 dienen, voor zover niet opgevolgd alsnog in acht te worden genomen;

- het eigen vermogen dient alsnog met circa 13 miljoen te worden verlaagd, omdat de investeringsaftrek 1975 en 1976 ten onrechte in één bedrag in mindering is gebracht op de belastinglast;

- het waarderingssysteem van de Bouwrekening ontwikkelingsprojecten Polyzathe is onjuist, is onvoldoende toegelicht en bevat een ongeoorloofde systeemwijziging.

\section{Aanwijzingen OK 1977}

Sobi doelt op de door de OK gegeven aanwijzingen terzake van de ratio's, van de beurswaarde van de strategische deelnemingen en van de doorzetverplichtingen M.O.T.')

De OK verwerpt deze vordering van Sobi, omdat de HR het arrest inzake de jaarrekening 1977 heeft vernietigd. Er bestaat derhalve voor Pakhoed geen verplichting om die aanwijzingen op te volgen. De OK voegt hieraan nog toe dat eiseres ook in de onderhavige procedure had kunnen stellen dat de jaar. rekening 1978 op de punten, waarop de aanwijzingen 1977 betrekking hebben, te kort schiet. Eiseres heeft dit evenwel niet gedaan.

\section{Investeringsaftrek}

Sobi, onder invloed van de opvattingen omtrent de verwerking van WIR-pre. mies $^{2}$ ), stelt dat de investeringsaftrek 1975 en 1976 had moeten worden geëga liseerd naar gelang de terugbetalingsverplichting dan wel naar gelang de le. vensduur. Nu dit niet is gebeurd, is het eigen vermogen met circa 13 miljoen te hoog voorgesteld.

Zie bespreking van dit arrest in het MAB.

Zie Voorontwerp t/an Beschouzingen, aflevering 6, februari 1979 (ook opgenomen in Richlijhen voor de Jaarrekening, juni 19501 
Pakhoed acht de gedragslijn dat de voordelen uit hoofde van investeringsaftrek ineens worden genoten - door vermindering van de belastinglast in overeenstemming met de norm van art. 2:31 l BW. Anders dan de WIR premie is de investeringsaftrek een bijdrage van de fiscus aan het resultaat. Zij voert verder nog aan dat gedeeltelijke restitutie binnen zes jaar wel mogelijk is, maar niet aannemelijk. In het kader van de continuiteitsveronderstelling is er geen reden om te veronderstellen dat binnen zes jaar vervreemding van de duurzame activa zal plaats vinden. Men mag derhalve aannemen dat de toe. kenning van de investeringsaftrek definitief is, behoudens duidelijke aanwijzingen voor het tegendeel, waarvan bij Pakhoed geen sprake is. Zij merkt nog op dat, ook als de zienswijze van Sobi wordt gevolgd, zij het niet-geëgaliseerde deel onder het eigen vermogen zou opnemen. Van een schuld, overlopende post of voorziening is immers geen sprake.

De OK acht het systeem niet in strijd met de norm van art. 2:311 BW. Daar ook van een voornemen tot vervreemding geen sprake is, heeft Pakhoed te. recht geen rekening gehouden met een desinvesteringsbijtelling.

Het oordeel van de OK zal weinigen verbazen. De door Pakhoed gevolgde gedragslijn werd veelvuldig toegepast. De voordelen uit hoofde van investeringsaftrek worden gewoonlijk gezien als een definitief verschil tussen het be. drijfseconomische en fiscale winstbegrip, met als gevolg dat de te verantwoorden belastinglast in de winst- en verliesrekening lager is dan overeenkomt met het belastingtarief toegepast op het bedrijfseconomische winstsaldo. Dit is ge heel in overeenstemming met de opvatting van het Tripartiete Overleg (TO), zij het dat dit orgaan een voorkeur uitspreekt voor toerekening aan de gebruiksjaren van de activa ${ }^{3}$.

Terzake van de opvatting van Pakhoed dat in de zienswijze van Sobi het nietgeëgaliseerde deel onder het eigen vermogen opgenomen zou mogen wor. den, kan men verschillend denken. Men kan de verlichting in belastingdruk ook toevoegen aan de voorziening voor latente belastingen en deze geleidelijk doen verminderen in overeenstemming met de steeds lagere waarde van het actief. Na zes jaar kan het restant geheel vrijvallen, aannemende dat het actief in gebruik blijft. Uitgaande van het ontbreken van het voornemen tot afstoting ligt de zo juist beschreven gedragslijn niet voor de hand. De voorkeur van het TO spreekt meer aan (matching principle). Deze voorkeur leidt tot de invoering van een egalisatierekening, waarvan het karakter m.i. die van overlopende post is. Terzake van de egalisatierekening WIR-premies merkt het TO op dat deze niet tot het eigen vermogen behoort ${ }^{4}$ ).

\section{Bouwrekening ontwikkelingsprojecten Polyzathe}

Pakhoed waardeert blijkens de toelichting op de jaarrekening ontwikkelingsprojecten van Polyzathe op basis van geïnvesteerde bedragen. Zij maakt hierbij onderscheid tussen projecten in voorbereiding en projecten in uitvoering. De waardering van de projecten in voorbereiding (incl. rente) wordt zonodig verminderd met geprognotiseerd verlies. De waardering van de projecten in uitvoering, voor zover verkocht, wordt vermeerderd met de geprognotiseerde

\footnotetext{
9) Voorontuerp wan Beschouwingen hoofdstuk VI 4, al. 8, december 1975; ook opgenomen in Richtlignen vaor de jaarrekening.

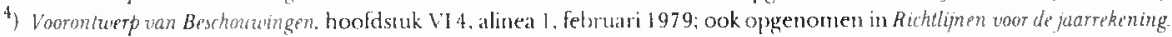


winst naar rato van de bouwstand, dan wel verminderd met het geprognotiseerd verlies. De waardering van projecten in uitvoering, voor zover niet verkocht, geschiedt, indien de opbrengstwaarde minus afbouwkosten lager is dan de geïnesteerde bedragen, op de opbrengstwaarde minus afbouwkosten.

Uit de processtukken blijkt dat bij projecten in voorbereiding geactiveerd worden de aan derden betaalde bedragen, voornamelijk voor grond en voorts bouwrente (enkelvoudig berekend). Is de marktwaarde lager dan wordt het verlies terstond genomen. Bij projecten in uitvoering worden geactiveerd de grond, de voorbereidingskosten, de aanneemsom (alles wordt door derden gebouwd, in het algemeen tegen vaste aanneemsommen), een voorgecalculeer. de toeslag algemene fabricagekosten (exclusief kosten van management, secretariaat, financiële administratie en personeelskosten), de aan derden betaalde verkoopkosten zoals makelaarskosten (alleen voor zover verkocht) en rente, enkelvoudig berekend over de geïnvesteerde bedragen (exclusief ingecalculeerde winst) onder aftrek van ontvangen termijnen. Er wordt nooit meer geactiveerd dan de geraamde opbrengsten minus afbouwkosten. Het rentepercentage is een gewogen gemiddelde over het totale complex vreemd vermogen (inclusief voorzieningen en leverancierskredieten met rentepercentage van nul), dat halfjaarlijks wordt bijgesteld.

Sobi is van oordeel dat uit de jaarrekening niet blijkt wat onder geïnvesteerde bedragen wordt verstaan. Zij eist - in navolging van het oordeel van de OK inzake de voorraadwaardering bij $\mathrm{KSH}^{5}$ ) - dat uiteengezet wordt of sprake is van een integrale dan wel partiële kostprijs, dat aangegeven wordt welke waar. deringsgrondslag voor de verschillende kostencategorieën wordt toegepast en dat bij een partiële kostprijs in algemene termen wordt vermeld welke kostencategorieën niet zijn opgenomen. $\mathrm{Zij}$ acht het activeren van verkoopkosten bovendien onjuist en in strijd met art. 39 lid 2 vierde richtlijn van de EG inzake de jaarrekening. Ook acht Sobi het nemen van winst op verkochte gedeelten naar rato van de bouwstand in strijd met het realisatiebeginsel en voorzichtig. heidsbeginsel. Zij ziet ook strijdigheid met art. 31 lid lc van de vierde EG.richtlijn. Voorts acht Sobi het activeren van rente over de geïnvesteerde bedragen onjuist en in strijd met de Beschouwingen en art. 39 lid 4 van de zo juist ge. noemde richtlijn. Voor het geval de OK de wijze waarop Pakhoed de winst voor Polyzathe, de kosten en de rente verantwoordt, toelaatbaar acht, eist Sobi dat Pakhoed aangeeft in hoeverre het resultaat van Polyzathe daardoor wordt beïnvloed. Tenslotte is Sobi van oordeel dat Pakhoed een systeemwijziging heeft ingevoerd doordat Polyzathe - voorheen een 50\%-deelneming, thans een $100 \%$ deelneming - in de consolidatie is begrepen met als gevolg dat niet-gerealiseerde winsten op vlottende activa worden genomen en dat rente op vlot. tende activa en verkoopkosten op vlottende activa wordt geactiveerd. Zij vor. dert daarom dat de invloed daarvan op het vermogen en het resultaat wordt vermeld.

De bezwaren van Sobi worden hierna achtereenvolgens besproken, waarbij wordt onderscheiden in (1) onduidelijke toelichting, (2) verkoopkosten, (3) winstneming, (4) geactiveerde rente, (5) invloed op het resultaat Polyzathe en (6) sys. teemwijziging.

\footnotetext{
5) Zie de bespreking van dit arrest in het $M A B$, november 1978 door G. C. J van Loon.
} 


\section{Onduidelijke toelichting}

De OK is van oordeel dat het door Pakhoed toegepaste systeem niet in strijd is met normen die in het maatschappelijk verkeer als aanvaardbaar worden beschouwd mits duidelijk toegelicht (art. 2:31 1 BW). De OK beschouwt derhal. ve „een duidelijke toelichting” te behoren tot de zo juist bedoelde normen. De OK acht in het onderhavige geval de toelichting niet duidelijk, omdat onvol. doende blijkt dat bij projecten in voorbereiding onder geïvesteerde bedragen worden verstaan de directe kosten verhoogd met rente en bij projecten in uit. voering onder geïnvesteerde bedragen wordt verstaan de som van de directe en een deel van de indirecte kosten, verhoogd met rente. De OK is voorts van oordeel dat niet blijkt met welke kostencategorieën wordt rekening gehouden en geeft daarom tevens als aanwijzing dat in algemene termen moet worden vermeld met welke indirecte kosten wordt rekening gehouden.

Uit dit oordeel van de OK blijken enige afwijkingen van het door Sobi op dit aspect gevorderde en dus ook ten opzichte van het oordeel van de OK in. zake de jaarrekening 1974/75 van KSH. In de KSH-procedure gaf zoals reeds is opgemerkt de OK een aanwijzing die letterlijk overeenkomt met hetgeen Sobi in de onderhavige procedure omtrent de toelichting aanvoert. De OK baseerde zich toen op art. 2:308 BW de doelbepaling van de jaarrekening en baseert zich thans op art. 2:311 BW (normen, die ...). Voorts verlangde de OK in de KSH-procedure dat in algemene termen wordt vermeld welke kosten. categorieën niet in de kostprijs zijn opgenomen, terwijl de OK nu verlangt dat in algemene termen wordt vermeld welke indirecte kosten in de kostprijs zijn opgenomen. Op de vordering van Sobi dat van de in de kostprijs opgenomen kostencategorieën de waarderingsgrondslag moet worden vermeld gaat de $\mathrm{OK}$ in de onderhavige procedure niet in.

Het oordeel van de OK maakt wel duidelijk dat de OK een waardering beneden de integrale kostprijs aanvaardbaar vindt. Het TO is nadrukkelijk van oordeel dat een minder dan evenredig toerekenen van de indirecte bewer. kingskosten niet aanvaardbaar is ${ }^{6}$ ). De vierde EG.richtlijn gaat evenwel van het beginsel uit dat indirecte bewerkingskosten voor een redelijk deel mogen worden geactiveerd (art. 39 lid 2 juncto art. 35 lid 3 b).

\section{Verkoopkosten}

De OK neemt aan dat Sobi met haar bezwaar tegen het activeren van verkoop. kosten bedoelt dat indirecte verkoopkosten niet mogen worden geactiveerd. Waarom de OK tot deze veronderstelling komt, is mij niet duidelijk. Sobi verwijst naar art. 39 lid 2 van de vierde EG.richtlijn. In dit artikel staat een duidelijk verbod voor het activeren van verkoopkosten zonder enig onderscheid in directe en indirecte verkoopkosten. Er is dus geen reden om te veronderstellen dat Sobi alleen indirecte verkoopkosten bedoelt. In de opvatting van het TO mogen indirecte verkoopkosten alleen worden geactiveerd indien er een dui. delijk verband bestaat met het op de huidige plaats en in de huidige staat bren.

5) Richdlijnen voor de jaarrekening hoofdstuk 2.06. al. 212. 
gen van de voorraden en is het activeren van directe verkoopkosten niet toe. gestaan $\left.{ }^{7}\right)$.

De OK verwerpt het bezwaar van Sobi omdat duidelijk blijkt dat slechts bij reeds verkochte, doch nog niet opgeleverde projecten met aan derden betaal de directe verkoopkosten wordt rekening gehouden. Zij is van oordeel dat Pakhoed in haar systeem deze kosten terecht activeert. Dit oordeel van de OK is juist nu bij verkochte projecten naar rato van de bouwstand de winst wordt verantwoord.

\section{Winstneming}

Het bezwaar van Sobi tegen het verantwoorden van winst bij verkochte pro. jecten naar rato van de bouwstand wordt door de OK terecht verworpen. Het systeem is in overeenstemming met art. 2:311 BW, het is niet ongebruikelijk en het doet geen afbreuk aan een verantwoord oordeel omtrent de financiële uitkomsten van het gevoerde beleid (art. 2:308 BW). Ik voeg hieraan nog toe dat de gedragslijn ook in overeenstemming is met de opvatting van het TO.

\section{Geactiveerde rente}

De bezwaren van Sobi tegen het activeren van rente zijn gebaseerd op de Beschouwingen van het $\mathrm{TO}^{8}$ ) en op de vierde EG-richtlijn (art. 39). Het beroep van Sobi op deze stukken is niet geheel duidelijk. Het TO merkt op „Bij waardering (...) van de voorraden van in de onderneming voortgebrachte goederen verdient de integrale kostprijs de voorkeur (. . .); in deze kostprijs zal een rentebestanddeel zijn begrepen. Incalculeren van rente mag er niet toe leiden dat de waardering hoger is dan (. . .) indien de goederen van derden zouden zijn betrokken. Betreft het goederen die niet van derden kunnen worden betrokken dan dient de waardering (. . .) niet hoger te zijn dan de directe opbrengstwaarde .... De vierde EG-richtlijn geeft Lid-Staten de bevoegdheid om toe te laten dat rente op vreemd vermogen in de vervaardigingskosten van voorraden, voor zover zij op de produktieperiode betrekking hebben, wordt opgenomen, mits hiervan in de toelichting melding wordt gemaakt (art. 39 lid 2, juncto art. 35 lid 4).

De OK verwerpt terecht het bezwaar van Sobi. Zij oordeelt dat tot de kosten in beginsel ook behoren de kosten van het vermogensbeslag. De wijze waarop Pakhoed de rente activeert, is in een geval als het onderhavige niet in strijd met art. 2:311 BW. Hierbij neemt de OK in aanmerking dat onderhanden projecten niet hoger worden gewaardeerd dan de geprognotiseerde opbrengst. De subsidiaire stelling van Sobi dat als activering wel toelaatbaar is, slechts een proportioneel deel in overeenstemming met de verhouding rentedragend vreemd vermogen/eigen vermogen voor activering in aanmerking komt, wordt door de OK eveneens verworpen. Er bestaat in een geval als het onderhavige geen vaste algemeen erkende maatstaf voor de rentetoerekening. De OK acht het toerekeningssysteem aanvaardbaar. 


\section{Invloed op het resultaat Polyzathe}

Sobi heeft nog geëist dat in ieder geval inzicht door Pakhoed moet worden ge geven in de mate waarin het resultaat Polyzathe als gevolg van de wijze van winstneming en van de activering van kosten en rente, wordt beïnvloed. $\mathrm{Zij}$ baseert zich hierbij op art. 2:308 $\mathrm{BW}$. Pakhoed stelt hier tegenover dat van be. lang is dat het waarderingssysteem voldoet aan art. 2:311 BW (normen die ...) en dat voldaan wordt aan art. 2:335 lid 2 BW (resultaatbijdrage per produkt. groep).

De OK is het met Pakhoed eens. Het systeem, mits duidelijk toegelicht, is niet in strijd met art. 2:311 BW. Noch de voor de bedrijfstak aanvaardbare maatstaven (art. 2:335 lid $2 \mathrm{BW}$ ), noch de doelbepaling van de jaarrekening (art. 2:308 BW), brengen mee dat de door Sobi gewenste gegevens moeten worden verstrekt.

\section{Systeemwijziging}

Polyzathe is eind 1977 in plaats van een 50\%-deelneming van Pakhoed een $100 \%$ deelneming van Pakhoed geworden, waarvan de resultaten in 1978 voor het eerst in de consolidatie zijn betrokken. Pakhoed voert hierbij terecht aan dat het voor het eerst in consolidatie betrekken geen systeemwijziging inhoudt. De wijze waarop winsten in aanmerking worden genomen alsmede rente en verkoopkosten worden geactiveerd is bij Polyzathe niet gewijzigd.

Uit het voorgaande is gebleken dat de OK de wijze waarop Pakhoed de win sten, de rente en de verkoopkosten behandelt, juist vindt. Nu Pakhoed gemotiveerd aanvoert dat deze behandeling ook reeds in 1977 plaats vond en daarin in 1978 geen wijziging heeft plaatsgevonden hetgeen door de accountant is be vestigd, verwerpt de OK de eis van Sobi. Expliciet bevestigt de OK de zienswijze van Pakhoed dat het voor het eerst in de consolidatie betrekken niet betekent dat de bepaling van het resultaat op een andere grondslag berust.

\section{Slotopmerkingen}

Dit arrest van de OK laat zien dat de OK de partijen en de accountant alle ge. legenheid geeft om hun zienswijzen kenbaar te maken. De opbouw per strijd punt is gewoonlijk: zienswijze accountant, eisen van Sobi, antwoord van Pak hoed en oordeel van de OK. De OK komt hierbij steeds tor een gefundeerd oordeel, een enkel detail daargelaten.

Het alleszins bevredigende oordeel betekent voor Pakhoed slechts één aanwijzing nl. het geven van een duidelijke toelichting op de post onderhanden projecten. De OK acht deze tekortkoming niet van zodanig gewicht dat dit tot vernietiging (van de vaststelling en / of goedkeuring) van de jaarrekening moet leiden. Zij beperkt de aanwijzing tot de jaarrekeningen over toekomstige jaren.

Het oordeel van de OK houdt in dat Sobi niet alleen de eigen proceskosten moet betalen, maar ook $75 \%$ van de door de OK voor Pakhoed begrote kosten van $f 2.595,-$, dus $f 1.890,-$. Het ongelijk van Sobi is door de OK naar mijn mening aan de zuinige kant bezien. Hierbij laat ik rusten dat in werkelijkheid de kosten van Pakhoed aanzienlijk hoger zijn.

Afsluitend merk ik nog op dat Sobi veelvuldig een beroep doet op de vierde 
EG-richtlijn inzake de jaarrekening. Sobi doet hierbij voorkomen dat deze richt. lijn geldend recht is. Dit is natuurlijk niet waar; inmiddels is het ontwerp van Wet tot aanpassing van de Nederlandse wetgeving aan de vierde EG-richtlijn bij de Tweede Kamer ingediend. Een voorzichtige schatting lijkt dat de Nederlandse wet eind 1982 is gewijzigd en dat de bepalingen op zijn vroegst met in. gang van het verslagjaar 1983 in werking treden. Een en ander neemt niet weg dat de OK de wetsvoorschriften anticiperend d.w.z. rekening houdend met de vierde EG.richtlijn kan interpreteren. Het beroep dat Sobi op deze richtlijn deed, bleek evenwel in hoofdzaak ten onrechte. De richtlijn vormt eerder een ondersteuning voor de zienswijze van Pakhoed dan die van Sobi. Daarnaast hebben de Lid-Staten van de EG de bevoegdheid verdergaande voorschriften te geven. 